\title{
Some insights into the reliability and validity of the Ayer Battery of Emotional Responses
}

Received (in revised form): 16th February, 2005

\section{William L. James}

earned his PhD in marketing at the Krannert Graduate School of Management of Purdue University. Dr James' research interests are primarily in the fields of advertising and strategic management. His research has appeared in marketing and management journals including the Journal of Marketing Research, the Strategic Management Journal and the Journal of Advertising Research.

\section{Arthur J. Kover}

earned his PhD in sociology at Yale University. During 23 years in the advertising industry he has held research executive positions at N.W. Ayer, Cunningham \& Walsh, J. Walter Thompson and other advertising agencies. He is a former president of the Market Research Council and former editor of the Journal of Advertising Research.

\section{Brenda S. Sonner}

earned her PhD in marketing at Florida State University. Her research interests are all facets of marketing communications, including political marketing and sales promotions. Her research has appeared in journals such as the Journal of Advertising Research and the Journal of Political Marketing.

\section{James P. Keeler}

earned his $\mathrm{PhD}$ in economics and business at Indiana University. His research interests are in the airline industry and the Austrian business cycle theory. His research has appeared in journals such as the Review of Austrian Economics the Southern Economics Journal and the International Journal of Transport Economics.

William L. James

Marketing \& International Business, 222 Weller Hall, 134 Hofstra University, Hempstead, NY 11549, USA.

Tel: +1 516463 5333; e-mail:

billjames@covad.com or mktwlj@hofstra.edu

\section{INTRODUCTION}

'Emotional kick' is an integral part of advertising effectiveness. As Zeitlin and Westwood ${ }^{1}$ point out, 'No advertising communication can be neutral in its emotional content since then it would be communicating nothing at all'. The Rossiter and Percy model, ${ }^{2}$ a commonly used model of advertising, explicitly includes emotion as an integral component of effective advertising.

Interest in the role that emotion plays in advertising effectiveness can be traced back to the 1980 s. $^{3-5}$ During this time, researchers established linkages between affective responses and attitudes towards 
both the advertisement and the brand, as well as purchase intentions. ${ }^{6-15}$ This interest in emotions continues to this day. ${ }^{16,17}$ Indeed neuromarketing, the use of MRI technology in market research studies, is producing evidence to show that advertising messages and brand names produce an emotional response in consumers. ${ }^{18-20}$ Whether or not this neuromarketing technique can prove to be a cost-effective investigative tool remains to be seen.

Critical to all research efforts, of course, is the need to measure consumers' emotional responses to advertising. Many of the pencil and paper measures from previous studies have been reprinted in various editions of the 'Marketing Scales Handbook'. ${ }^{21}$ All of these scales/measures purport to measure some aspect of affect, though they vary in terms of what they measure and how wide their application is.

Unfortunately, with a few exceptions such as the BBDO picture-oriented test, ${ }^{22}$ most of the measures used in academic studies cannot be easily applied commercially. On the other hand, commercially derived measures are not usually available to academic researchers. One exception is the battery of emotional responses, developed at N.W. Ayer and reported by Kover and Abruzzo. $^{23}$ This scale has been used successfully in academic research ${ }^{24-26}$ and through these efforts has demonstrated its efficacy in differentiating the reactions of various groups to advertising messages.

The focus of this research effort is to assess further the reliability and validity of the N.W. Ayer Battery of Emotional Responses. This research examined the issues of concurrent validity, predictive validity and reliability utilising four separate samples, none of which were used in the development of the original scale. If the reliability and validity of the Ayer Battery can be established, it will provide another measure of emotional responses to advertising, and one that is useful for both academic and commercial researchers.

\section{ORIGINS OF THE AYER BATTERY OF EMOTIONAL RESPONSES}

In much commercial advertising research the emotional impact of an advertisement is ignored. This is probably because of the difficulty of rapid and simple measurement of emotions. During the 1980s N.W. Ayer (then the oldest advertising agency in the USA) began the task of developing a simple measurement of emotional responses to advertising. The agency commissioned Rajeev Batra, then at Columbia University, to comb the existing psychological literature on emotion and mood and extract as many descriptions as possible.

This project resulted in the development of a long list of words and short phrases used in the literature to describe emotions, moods and states of feeling. Researchers at N.W. Ayer (primarily Joseph Abruzzo, Arthur Kover and Sidney Lister) then reduced this list in three ways: (1) eliminating redundancies; (2) eliminating a few descriptors that could not be easily understood; and (3) eliminating descriptors (ie terror, ecstasy) not normally elicited by advertising. The resulting list still contained more than 50 items. A nationally representative sample of consumers then rated each word/phrase as a response to a broad set of 45 television commercials. Based on these responses, the words/phrases were clustered through factor analysis into 16 factors. Each factor was then given a weight through regression with the dependent variable being purchase interest. Further testing involving two more samples resulted in a battery that the agency viewed as reliable and valid. 
Table 1: N.W. Ayer Battery of Emotional Responses with Instructions

NOW, thinking just of this commercial. What emotions did this commercial arouse in you. Check as many or as few items as you think appropriate in Column A.

\begin{tabular}{|c|c|c|c|}
\hline & $A$ & & B \\
\hline Aroused, playful & [ ] & Aroused, playful & [ ] \\
\hline Embarrassed, guilty & {[]} & Embarrassed, guilty & [ ] \\
\hline Benefited, enlighten & [] & Benefited, enlighten & [ \\
\hline Affectionate, innocent & [] & Affectionate, innocent & [ \\
\hline Attentive, not bored & {[]} & Attentive, not bored & [ ] \\
\hline Virtuous, moral & [ ] & Virtuous, moral & [ ] \\
\hline Tense, anxious & [] & Tense, anxious & 1 \\
\hline Amazed, astonished & [] & Amazed, astonished & ] ] \\
\hline Disgusted, irritated & [ ] & Disgusted, irritated & [ ] \\
\hline Confident, proud & [] & Confident, proud & [] \\
\hline Suspicious, sceptical & [] & Suspicious, sceptical & [] \\
\hline Angry, powerless, sad & [] & Angry, powerless, sad & r \\
\hline Wishful, hopeful, desirous & [] & Wishful, hopeful, desirous & [] \\
\hline Sorrowful, afraid & [ ] & Sorrowful, afraid & [] \\
\hline Serene, soothed & [] & Serene, soothed & [] \\
\hline Confused, uninformed & [ ] & Confused, uninformed & [ ] \\
\hline
\end{tabular}

It should be noted that, during the Battery's development, agency personnel did not differentiate between moods and emotions. Agency researchers were not concerned with the academic distinction between mood and emotion; they only wanted to devise a battery that worked. It is also important to note that the Battery was heuristically derived and thus has ties to no particular theory. Details of its development were presented at a Marketing Science Institute Conference. ${ }^{27}$ The final Battery is presented in Table 1.

\section{METHODOLOGY}

This current research effort utilised four very different samples to assess aspects of the reliability and validity of the Ayer Battery: (1) a traditional undergraduate student convenience sample from a suburban private Mid-Atlantic university; (2) a mature working student convenience sample from a small urban south-eastern state university; (3) a small but representative national sample of consumers; and (4) a stratified sample (large multinational shops and smaller agencies) of advertising agency creative personnel representing 11 New York agencies. Details of these samples can be found in Table 2 and in the articles where they were originally used. ${ }^{28-30}$ Utilising such different groups of subjects not only allowed them to examine the robustness of the Battery, it also allowed the researchers to use samples that are commonly used by academic researchers (ie sample 1 and sample 2, college students) and samples that are commonly used by practitioners (ie sample 4 , a national sample of consumers). This last sample, the consumers, was recruited by an independent research company (The Data Group) using a national random telephone sample. Selected participants were required to have a VCR unit in their home since they would be sent a VHS tape of the test commercials to view in their home and at their own pace.

A total of 15 commercials was tested among the samples. Each sample was exposed to six television commercials representing two product categories. The three commercials in each product 
Table 2: Sample sizes and demographics

\begin{tabular}{llll}
\hline & Respondents & Average age & Percent male \\
\hline Traditional undergraduate student sample & 116 & 21.33 & 44.8 \\
Mature working student sample & 114 & 32.44 & 45.1 \\
National consumer sample & 69 & 38.40 & 44.1 \\
Sample of New York advertising agencies' & 104 & 33.85 & 60.2 \\
$\quad$ creative professionals & & \\
\hline
\end{tabular}

Table 3: Distribution of responses by sample for split half reliability using uniform random number generator

\begin{tabular}{lll}
\hline & Subsample 1 & Subsample 2 \\
\hline Traditional undergraduate student sample & 348 & 348 \\
Mature working student sample & 337 & 347 \\
National consumer sample & 188 & 226 \\
Sample of New York advertising agencies' creative professionals & 323 & 295 \\
\hline
\end{tabular}

category consisted of: a commercial that had won a national award for creativity; a commercial that had won a national award for effectiveness; and a commercial judged to be average (neither great nor awful). Three commercials representing one product category (restaurants) were common across all four samples. The other three commercials represented another product category (either automobiles, sneakers or financial services) and varied for each sample.

Student samples and the agency sample watched the commercials in group settings. The consumer sample watched the commercials in their own homes at times of their choosing. After each exposure to a commercial, the subjects completed the Ayer Battery as well as indicating liking for the advertisement (five-point scale) and purchase interest (five-point scale). The Ayer Battery measures the presence or absence of each emotional response and then, as a relatively crude measure of intensity, which emotion was felt most strongly.

Each subject response was treated as if it were an independent observation. This approach is common among US advertising professionals although it may result in some bias since it treats all variation as if it were between respondents when in fact some of the variation is truly within respondent. Analyses were also conducted separately for each sample and subsample so that any systematic bias due to the nature of the sample could be avoided.

\section{ANALYSES}

\section{Concurrent validity}

Concurrent validity has been defined as the extent to which one measure can be used to estimate an individual's score on a different measure of the same variable. ${ }^{31}$ Liking for an advertisement and the Ayer Battery are both measures of affect, thus concurrent validity was assessed by multiple regressions utilising liking for the advertisement as the dependent variable and the items of the Ayer Battery as the independent variables. Each individual item in the Ayer Battery was treated as a separate, independent variable and each was coded as zero (response not selected) or one (response selected).

Each of the four samples was randomly split into two subsamples (see Table 3). The first analyses used regression on each of the subsamples to assess how well the Ayer Battery 
Table 4: Predictive ability (adjusted R squared) of Ayer Battery by subsample for liking the ad

\begin{tabular}{lll}
\hline & Subsample 1 & Subsample 2 \\
\hline Traditional undergraduate student sample & 0.52909 & 0.51657 \\
Mature working student sample & 0.57150 & 0.49418 \\
National consumer sample & 0.54758 & 0.54649 \\
Sample of New York advertising agencies' creative professionals & 0.68958 & 0.68146 \\
\hline
\end{tabular}

Table 5: Correlations between actual liking for the ad and predicted liking for the ad based on split half coefficients by subsample

\begin{tabular}{lll}
\hline & Subsample 1 & Subsample 2 \\
\hline Traditional undergraduate student sample & 0.7163 & 0.6619 \\
Mature working student sample & 0.7706 & 0.6924 \\
National consumer sample & 0.7341 & 0.7053 \\
Sample of New York advertising agencies' creative professionals & 0.8183 & 0.8034 \\
\hline
\end{tabular}

Table 6: Predictive ability (adjusted R squared) of Ayer Battery by subsample for purchase interest

\begin{tabular}{lll}
\hline & Subsample 1 & Subsample 2 \\
\hline Traditional undergraduate student sample & 0.45744 & 0.36846 \\
Mature working student sample & 0.46356 & 0.42249 \\
National consumer sample & 0.38181 & 0.42530 \\
Sample of New York advertising agencies' creative professionals & 0.50646 & 0.48993 \\
\hline
\end{tabular}

predicted liking for the advertisement. As Table 4 shows, the adjusted variance explained for these eight regressions ranged from 49 per cent to 68 per cent. The regression coefficients derived from the Table 4 results were then applied to the other half of the split sample from the same sampling frame. These predicted values were correlated with actual values of liking for the advertisement (see Table 5) resulting in correlations that ranged from 0.66 to 0.81 (or variance explained ranging from 44 per cent to 66 per cent). Both of these sets of analyses resulted in reasonably high values across all eight subsamples and provide consistent support for concurrent validation of the Ayer Battery.

\section{Predictive validity}

Predictive validity has been defined as the extent to which an individual's score on a variable can be predicted by measuring his or her performance (or score) on a related variable. ${ }^{32}$ The advertising industry accepts purchase interest is a reasonable proxy for purchase behaviour, ${ }^{33}$ thus predictive validity could be assessed by examining the degree to which the Ayer Battery predicted purchase interest. Multiple regressions were again used to predict purchase interest from the items in the Ayer Battery.

The results of these regressions (shown in Table 6) indicate the adjusted variance explained ranged from 36 per cent to 50 per cent. As was done in the preceding analyses, these regression coefficients were applied to the other half of the split sample from the same sampling frame. These predicted values were then correlated with actual values of purchase interest (see Table 7) resulting in correlations that ranged from 0.57 to 0.71 (or variance explained ranging from 32 per cent to 50 per cent).

Both sets of analyses provide support for the predictive validity of the Ayer 
Table 7: Correlations between actual purchase interest and predicted purchase interest based on split half coefficients by subsample

\begin{tabular}{lll}
\hline & Subsample 1 & Subsample 2 \\
\hline Traditional undergraduate student sample & 0.6627 & 0.5970 \\
Mature working student sample & 0.6566 & 0.6330 \\
National consumer sample & 0.6071 & 0.5750 \\
Sample of New York advertising agencies' creative professionals & 0.7103 & 0.6952 \\
\hline
\end{tabular}

Table 8: Split half correlations of checked emotions by subsample

\begin{tabular}{lll}
\hline & Kendall's Tau & Pearson's R \\
\hline Traditional undergraduate student sample & $0.912 p<0.001$ & $0.970 p<0.001$ \\
Mature working student sample & $0.933 p<0.001$ & $0.984 p<0.001$ \\
National consumer sample & $0.862 p<0.001$ & $0.983 p<0.001$ \\
Sample of New York advertising agencies' creative professionals & $0.912 p<0.001$ & $0.994 p<0.001$ \\
\hline
\end{tabular}

Table 9: Split half correlations of most strongly felt emotions by subsample

\begin{tabular}{lll}
\hline & Kendall's Tau & Pearson's R \\
\hline Traditional undergraduate student sample & $0.840 p<0.001$ & $0.971 p<0.001$ \\
Mature working student sample & $0.844 p<0.001$ & $0.985 p<0.001$ \\
National consumer sample & $0.828 p<0.001$ & $0.981 p<0.001$ \\
Sample of New York advertising agencies creative professionals & $0.826 p<0.001$ & $0.994 p<0.001$ \\
\hline
\end{tabular}

Battery. It is worthwhile observing that in all subsample analyses the Ayer Battery is better able to predict liking for the brand than purchase interest. This is further confirmation of the Ayer Battery's validity since it measures reactions to an advertisement as does liking for an advertisement. Purchase interest on the other hand is further removed from these two measures since it is influenced by more than just the advertisement.

\section{Reliability}

The most common traditional approaches to reliability such as Cronbach's coefficient alpha and factor analytic/structural equation approaches are not applicable since, unlike a scale, the Battery's items are not summed for an overall score. Thus another approach to measuring consistency was identified. The frequency with which the individual emotional responses in the Ayer Battery were selected was tabulated for each of the eight subsamples. These frequencies were then correlated across the subsamples within each sampling frame. The resulting correlations (Table 8) are very high with values of Kendall's Tau ranging from 0.862 to 0.933 , and Pearson's $\mathrm{r}$ ranging from 0.970 to 0.994 . This indicates a high level of consistency within the samples.

The Ayer Battery also asks respondents to indicate the emotion most strongly felt (a measure of intensity). Using the same approach to assess consistency, a count was made in each subsample of the frequency with which an individual emotional response in the Ayer Battery was selected as the emotional response most strongly felt. For each sampling frame the two frequency distributions were correlated (see Table 9). The values of Kendall's Tau ranged from 0.826 to 0.844 while the values for Pearson's $r$ ranged from 0.97 to 0.99 . These results 
confirm the earlier conclusion of substantial consistency within each sample and provide substantial evidence of reliability of the Ayer Battery.

\section{Consistency with the original N.W. Ayer study}

As an additional assessment of the reliability of the Ayer Battery, the results of the present study were compared to some of the results of the original Ayer study. All four samples were combined and a regression predicting purchase interest based on the 16 items was conducted. The directionality of the coefficients (significant positive, not significant, significant negative) was determined and then compared to the directionality of the coefficients in the original Ayer study. Three quarters (12 out of 16) of the coefficients had the same directionality. When the coefficients of the items that differed are examined, three of the four items in the present study have coefficients that are not significant but are in the same direction as the coefficients in the original Ayer study. This seems to be reasonably consistent with the original Ayer Battery results since the present study is more than a decade later and based upon a much smaller number of television commercials.

In addition, the directionality of the most strongly felt emotion was classified (positively related to purchase interest $=1$; negatively related to purchase interest $=0$ ) using the original Ayer results. The small number of occasions ( 3 per cent) when the most strongly felt emotion was not related to purchase interest (based on the original Ayer) study were ignored. T-tests were then conducted to determine if the direction of the most strongly felt emotion was related to purchase interest. The t-tests were conducted for each subsample and the results clearly show a significant relationship between these two variables (Table 10). When the most strongly felt emotion was positively related to purchase interest, mean purchase interest scores ranged from 3.01 to 3.47 . When the most strongly felt emotion was negatively related to purchase interest, mean purchase interest scores ranged from 1.35 to 1.69 .

Strongly felt emotions that seemed to be related to purchase interest were, in fact, linked to differences in actual purchase interest. Once again there is evidence of the validity of the Ayer Battery.

\section{CONCLUSIONS}

The objective of this work was to examine the reliability and validity of the N.W. Ayer Battery of Emotional Responses. Testing the Battery with an independent set of samples is a first step toward making this important measurement tool more legitimate within the larger academic community. The evidence consistently shows that the Battery is reliable and demonstrates both concurrent and predictive validity.

Another very positive finding was the lack of multicollinearity among the Ayer Battery items. The largest variance inflation factor was only 1.5 , well below the danger level of $10 .{ }^{34}$ This lack of multicollinearity indicates that the Ayer Battery retains its structure even after more than a decade.

As researchers strive to more fully understand the role that emotion plays in effective advertising, the Ayer Battery provides a simple, easy way to assess these emotional responses. Unlike the expensive scans utilised in neuromarketing, the pencil and paper tests developed by academic researchers but shunned by professionals, the Ayer Battery provides a simple measure that can be used in virtually any 
Table 10: T-Tests of mean purchase interest based upon directionality (positive or negative) of the most strongly felt emotion

\begin{tabular}{|c|c|c|}
\hline & Subsample 1 & Subsample 2 \\
\hline \multicolumn{3}{|c|}{ Traditional undergraduate student sample } \\
\hline Mean for positive emotions & 3.11 & 3.01 \\
\hline \multirow[t]{2}{*}{ Mean for negative emotions } & 1.63 & 1.69 \\
\hline & $\mathrm{t}=12.357, \mathrm{df}=286, p<0.001$ & $t=10.634, d f=284, p<0.001$ \\
\hline \multicolumn{3}{|l|}{ Mature working student sample } \\
\hline Mean for positive emotions & 3.44 & 3.47 \\
\hline \multirow{2}{*}{ Mean for negative emotions } & 1.52 & 1.62 \\
\hline & $t=16.347, d f=278, p<0.001$ & $t=15.084, d f=267, p<0.001$ \\
\hline \multicolumn{3}{|l|}{ National consumer sample } \\
\hline Mean for positive emotions & 3.40 & 3.41 \\
\hline \multirow[t]{2}{*}{ Mean for negative emotions } & 1.56 & 1.51 \\
\hline & $t=11.680, d f=130, p<0.001$ & $t=13.887, d f=159, p<0.001$ \\
\hline \multicolumn{3}{|c|}{$\begin{array}{l}\text { Sample of New York advertising agencies' } \\
\text { creative professionals }\end{array}$} \\
\hline Mean for positive emotions & 3.29 & 3.13 \\
\hline \multirow[t]{2}{*}{ Mean for negative emotions } & 1.36 & 1.35 \\
\hline & $\mathrm{t}=16.147, \mathrm{df}=307, p<0.001$ & $\mathrm{t}=14.716, \mathrm{df}=280, p<0.001$ \\
\hline
\end{tabular}

environment. It is an example of a free will gift from the normally closed world of business research. To the degree that it can find acceptance within both the academic community and among advertising professionals, the Ayer Battery may provide a way for these two groups to benefit from each other's research and narrow the divide between them.

Purists may cavil at the heuristic nature of the Ayer Battery and its mixing of emotion and mood. Yet, for the practitioners who have used it (and the academics who have written articles based on it) the Ayer Battery was robust and helpful. Furthermore, the Ayer Battery offers an interesting doorway to theory construction. In the development of the Ayer Battery, as with the early physical sciences, theory was formed to explicate common knowledge or everyday practice. The Battery seems to work; and is reliable and appears valid. Its development raises the question, 'how can theory be formed using this heuristic?'. In addition, the Ayer Battery offers an interesting doorway to theory construction. (In our new scientific language, 'heuristic' may be a synonym for folk knowledge.) Why, for instance, must mood and emotion be separated? What is the implicit chain of moods and feelings contained in this Battery? Perhaps the greatest benefit of the Ayer Battery is to open questions about the formation of theory and the application of practice to theory (and not the other way around). Studying the accepted, everyday practices of advertising professionals and drawing from this knowledge may open the way for social scientists to develop new theories to explain how advertising affects consumers and the decisions they make.

\section{References}

\footnotetext{
1 Zeitlin, D. M. and Westwood, R. A. (1986) 'Measuring emotional response,' Journal of Advertising Research, Oct/Nov, pp. 34-44.

2 Percy, L. (1991) 'Understanding the mediating effect of motivation and emotion in advertising measurement', Eighth Annual ARF Copy Research Workshop, pp. 78-90.

3 Holbrook, M. B. and O'Shaughnessy, J. (1984) 'The role of emotion in advertising', Psychology and Marketing, Vol. 1, No. 2, pp. 45-64.

4 Mizerski, R. W. and White, J. D. (1986) 'Understanding and using emotions in advertising',
} 
Journal of Consumer Marketing, Vol. 3, No. 4, pp. 57-69.

5 Hecker, S. and Stewart, D. W. (1988) 'Nonverbal communication in advertising', Lexington Books, Lexington, MA.

6 Batra, R. and Ray, M. (1986) 'Affective responses mediating acceptance of advertising', Journal of Consumer Research, Vol. 13, September, pp. 234-249.

7 Holbrook, M. B. and Batra, R. (1987) 'Assessing the role of emotions as mediators of consumer response to advertising', Journal of Consumer Research, Vol. 14, pp. 404-420.

8 Edell, J. A. and Burke, M. C. (1987) 'The power of feelings in understanding advertising efects', Journal of Consumer Research, Vol. 4, pp. 421-433.

9 Machleit, K. A. and Wilson, R. D. (1988) 'Emotional feelings and attitude toward the advertisement: The roles of brand familiarity and repetition', Journal of Advertising, Vol. 17, No. 3, pp. 27-35.

10 Edell, J. A. (1988) 'Nonverbal effects in ads: A review and synthesis', in Hecker, S. and Stewart, D. W. (eds) 'Nonverbal communication in advertising', pp. 11-28.

11 Dichter, E. (1988) 'Testing nonverbal communications', in Hecker, S. and Stewart, D. W. (eds) 'Nonverbal communication in advertising', pp. $29-42$.

12 Homer, P. M. and Yoon, S-G. (1992) 'Message framing and the interrelationships among ad-based feelings, affect and cognition', Journal of Advertising, Vol. 21, No. 1, pp. 19-32.

13 Morris, J. (1995) 'SAM: The self-assessment manikin - An efficient cross cultural measurement of emotional response', Journal of Advertising Research, Vol. 35, No. 6, November/December, pp. 63-68.

14 Batra, R., Myers, J. G. and Aaker, D. A. (1995) 'Advertising management', 5th edn, Prentice Hall, Upper Saddle River, NJ.

15 Hitchon, J. C. and Thorson, E. (1995) 'Effects of emotion and product involvement on the experience of repeated commercial viewing, Journal of Broadcasting and Electronic Media, Vol. 39, No. 3, Summer, pp. 376-389.

16 Hall, B. F. (2004) 'On measuring the power of communications', Journal of Advertising Research, Vol. 44, No. 2, June, pp. 181-187.

17 Young, C. E. (2004) 'Capturing the flow of emotion in television commercials: A new approach', Journal of Advertising Research, Vol. 44, No. 2, June, pp. 202-209.
18 Blakeslee, S. (2004) 'Say the right name and they light up', 7th December, www.nytimes.com.

19 Carmichael, M. (2005) 'Neuromarketing: Is it coming to a lab near you,' accessed on 13th January, 2005 at www.pbs.org/wgbh/pages/frontline/ shows/persuaders/etc/neuro.html.

20 McClure, S. M., Li, J., Tomlin, D., Cypert, K. S., Montague, L. M. and Montague, P. R. (2004) 'Neural correlates of behavioral preference for culturally familiar drinks', Neuron, Vol. 44, No. 2, October, pp. 379-387.

21 Bruner III, G. C., James, K. E. and Hensel, P. J. (2001) 'Marketing scales handbook: A compilation of multi-item measures, Volume III', American Marketing Association, Chicago, Illinois.

22 Yoon, C. (1991) 'Tears, cheers, and fears: The role of emotions in advertising', Marketing Science Institute Report No. 91-112, Marketing Science Institute, Cambridge, MA.

23 Kover, A. J. and Abruzzo, J. (1993) 'The Rossiter-Percy grid and emotional response to advertising: An initial evaluation', Journal of Advertising Research, Vol. 33, No. 6, pp. 21-27.

24 Kover, A. J., Goldberg, S. M. and James, W. L. (1995) 'Creativity vs. effectiveness? An integrating classification for advertising', Journal of Advertising Research, Vol. 35, No. 6, pp. 29-40.

25 Kover, A. J., James, W. L. and Sonner, B. S. (1997) 'To whom do advertising creatives write? An inferential answer', Journal of Advertising Research, Vol. 37, No. 1, January/February, pp. 41-53.

26 James, W. L. and Sonner, B. S. (2001) 'Just say no to traditional student samples', Journal of Advertising Research, Vol. 41, No. 5, September/October, pp. 63-71.

27 Yoon (1991) op. cit.

28 Kover, Goldberg and James (1995) op. cit.

29 Kover, James and Sonner (1997) op. cit.

30 James and Sonner (2001) op. cit.

31 Tull, D. and Hawkins, D. I. (1993) 'Marketing research: Measurement \& method', 6th edn, MacMillan, New York.

32 Ibid.

33 Haley, R. I. and Baldinger, A. L. (1991) 'The ARF copy validity project', Journal of Advertising Research, Vol. 31, No. 2, April/May, pp. 11-33.

34 Sharma, S. and James, W. L. (1981) 'Latent root regression: An alternate procedure for estimating parameters in the presence of multicollinearity', Journal of Marketing Research, Vol. XVIII, May, pp. 154-161. 